\title{
Polymer-Drug Conjugates in Inflammation Treatment
}

\author{
E. KOZIOLOVÁ ${ }^{1}$, K. VENCLÍKOVÁ ${ }^{1}$, T. ETRYCH ${ }^{1}$ \\ ${ }^{1}$ Institute of Macromolecular Chemistry of the Czech Academy of Sciences, Prague, Czech \\ Republic
}

Received May 24, 2018

Accepted June 28, 2018

\section{Summary}

Inflammation is a vital defense mechanism of living organisms. However, persistent and chronic inflammation may lead to severe pathological processes and evolve into various chronic inflammatory diseases (CID), e.g. rheumatoid arthritis, multiple sclerosis, multiple sclerosis, systemic lupus erythematosus or inflammatory bowel diseases, or certain types of cancer. Their current treatment usually does not lead to complete remission. The application of nanotherapeutics may significantly improve CID treatment, since their accumulation in inflamed tissues has been described and is referred to as extravasation through leaky vasculature and subsequent inflammatory cell-mediated sequestration (ELVIS). Among nanotherapeutics, water-soluble polymer-drug conjugates may be highly advantageous in CID treatment due to the possibility of their passive and active targeting to the inflammation site and controlled release of active agents once there. The polymer-drug conjugate consists of a hydrophilic biocompatible polymer backbone along which the drug molecules are covalently attached via a biodegradable linker that enables controlled drug release. Their active targeting or bio-imaging can be achieved by introducing the cell-specific targeting moiety or imaging agents into the polymer conjugate. Here, we review the relationship between polymer conjugates and inflammation, including the benefits of the application of polymer conjugates in inflammation treatment, the anti-inflammatory activity of polymer drug conjugates and potential polymer-promoted inflammation and immunogenicity.

\section{Key words}

Inflammation - Polymer conjugates - Anti-inflammatory nanotherapeutics • Immunogenicity

\section{Corresponding author}

E. Koziolová, Institute of Macromolecular Chemistry of the Czech Academy of Sciences, Heyrovského nám. 2, 16206 Prague 6, Czech Republic. E-mail: koziolova@imc.cas.cz

\section{Introduction}

The past few decades have witnessed an exponential growth in nanotechnology-based therapeutic approaches, including numerous nanosized drug delivery systems or diagnostics, being developed to improve treatment or diagnosis of various diseases. Since cancer is one of the main causes of death worldwide, the enhancement of anticancer treatment has been the major driving force behind nanomedicine design. Nevertheless, chronic inflammatory diseases (CID), e.g. rheumatoid arthritis, multiple sclerosis, systemic lupus erythematosus or inflammatory bowel diseases, have a substantial socioeconomic impact, since their prevalence is very high. The current therapy can reduce disease symptoms, though it cannot ensure a complete cure and patient quality of life is very limited, involving chronic pain states, surgical interventions and incapacity for work (El-Gabalawy et al. 2010). In addition, persistent chronic inflammation is considered as a potential risk factor in the development of various severe diseases, including cancer, diabetes, atherosclerosis or Alzheimer's and Parkinson's disease (Chen et al. 2018).

Remarkably, limited attention has been paid to the development of inflammation-targeted therapy based on nanomedicines, although many strategies utilized in tumor-targeted drug delivery could be applied for drug delivery to inflammation sites (Coussens and Werb 
2002). With an increasing number of clinical trials and approvals of nanotechnology-based application in medicine, it is essential to investigate their detailed impact on human physiology and pathophysiology and to evaluate their potential immunogenicity and pro-inflammatory effect.

The common denominator of nanosized systems is their size, which is generally $<100 \mathrm{~nm}$ in at least one dimension. However, their chemical structure, behavior in biological fluids and thus their interaction with biological systems at the molecular, cellular or organ level may be diametrically different. Nanosized drug carriers can considerably prolong drug circulation in the blood, improve their pharmacokinetics and minimize drug side effects (Ikoba et al. 2015). Among nanomedicines, water-soluble polymer-drug conjugates may be highly beneficial in CID treatment due to their potential passive and active targeting to the inflammation site and the controlled release of active agents once there. Generally, the polymer conjugates consist of a watersoluble polymer backbone along which various drug molecules are attached via biodegradable spacers (Kostka and Etrych 2016, Lidicky et al. 2016, Pola et al. 2016). Moreover, targeting moieties or imaging agents may be introduced to the polymer structure. Compared to widely used nanoparticles and liposomes with physically loaded drugs, water-soluble polymer conjugates exhibit lower immunogenicity and stimuli-responsive release of biologically active compounds (Natfji et al. 2017).

Here, we review the relationship between polymer conjugates and inflammation, namely the benefits of the application of polymer conjugates to inflammation treatment, the anti-inflammatory activity of polymer-drug conjugates and potential polymer-promoted inflammation and immunogenicity.

\section{Inflammation}

Inflammation is immune system defense mechanism vital for removing harmful stimuli that arise during infection or injury and initiating the healing process. However, dysregulation of the immune response and inadequate resolution may lead to chronic inflammation with severe clinical symptoms (Headland and Norling 2015). Due to the complexity of inflammation process and its resolution, the detailed description of inflammation mechanisms is out of scope of this article and it has been recently reviewed (Ashley et al. 2012, Sugimoto et al. 2016).

\section{Mechanisms of acute and chronic inflammation}

Inflammation is a strictly regulated cascade of immunological, physiological and behavioral processes. The first step is the recognition of the source of damage or infection. Pathogens are identified by their pathogenassociated molecular patterns (PAMPs). Damageassociated molecular patterns (DAMPs) are released by cells in reaction to stress, injury or necrosis (Bianchi 2007). In addition to pathogens, biomaterials, including some polymer materials, may also be recognized as foreign bodies and the immune reaction is initiated by protein interactions at their surface. Albumin, fibronectin or fibrinogen adsorb on biomaterials, which results in the recruitment of neutrophils and activation of resident mast cells, which represents the acute inflammatory response (Anderson et al. 2008).

Damage signals, based on PAMPs and DAMPs, are further recognized by transmembrane Toll-like receptors and intracellular binding domains and leucinerich-repeat-containing receptors. The subsequent cascade results in $\mathrm{NF}-\kappa \mathrm{B}$ activation and further expression of proinflammatory cytokines such as interleukins IL-1 $\beta$ and IL-6, interferon- $\gamma$ or tumor necrosis factor alpha (TNF $\alpha$ ) (Janssens and Beyaert 2003). These effectors attract immune cells such as neutrophils and monocytes. Activated neutrophils trigger cascades, which leads to bacterial killing and the release of reactive oxygen species (ROS) and proteinases into the extracellular space and the destruction of pathogens as well as host tissue (Wright et al. 2010). All these cascades lead to clinical signs of inflammation: heat, swelling, redness, pain and loss of function.

The last step of inflammation is its resolution. After neutrophils fulfill their function, an apoptotic pathway is triggered by cytokines produced by macrophages (Van Den Berg et al. 2001). Apoptotic neutrophils promote their own clearance by expressing find-me and eat-me signals, allowing the identification of a dying cell, and produce mediators that inhibit further neutrophils recruitment (Elliott et al. 2009).

Macrophages clear the neutrophils through so-called efferocytosis. Macrophages undergo a transition in phenotype from pro-inflammatory to pro-resolution macrophages that produce anti-inflammatory factors such as IL-10 or TGF- $\beta$ (Fadok et al. 1998). Resolution-phase macrophages secrete $\mathrm{T}$ - and B-lymphocytes chemoattractants and factors, which helps the recovery of tissue homeostasis (Rajakariar et al. 2008). More blood monocytes are recruited to the site where differentiation 
into pro-resolution macrophages is completed (Melnicoff et al. 1989).

When this balanced immune cascade fails, acute inflammation develops into chronic one. The initial cause of the reaction (bacteria, injury) is no longer present and immune cells attack host tissue and cause damage. In the case of chronic inflammation, neutrophils do not undergo apoptosis as intended and transform into long-living cells and continue producing ROS and proteases and damage the surrounding tissue. Without adequate signals from apoptotic neutrophils, macrophages do not change their phenotype towards pro-resolution. Inflammatory cells produce more pro-inflammatory cytokines and chemokines, which results in the production of oxygen and nitrogen reactive species (Fox et al. 2010). Chronic inflammation is often age-related and contributes to age-associated diseases (Franceschi and Campisi 2014).

\section{Chronic inflammatory diseases and inflammation-related diseases}

While acute inflammation is a normal host response to pathogen infections and tissue injury, its inadequate resolution can lead to the chronic stage, which is the precursor to a variety of diseases, e.g. CID or cancer. Although the clinical symptoms of diverse CID are distinctly different, the cellular processes in chronically inflamed tissues are similar, involving leukocyte migration, vasodilatation, activation of endothelial adhesive molecules, fluid extravasation, cellular influx and eventually angiogenesis or tissue fibrosis leading to the loss of tissue function (Bodolay et al. 2002). The current CID therapy includes the use of glucocorticoids (GC), non-steroidal anti-inflammatory drugs (NSAID) and immuno-modulating agents, since these diseases are often connected with autoimmunity. The drugs used alone or in combination suppress some symptoms and their use leads to partial treatment efficacy, but complete disease remission is very rare. The long-term administration of these agents causes severe side effects, e.g. nephrotoxicity, gastric ulceration, osteoporosis or hematotoxicity (Dinarello 2010).

Rheumatoid arthritis (RA). In RA, the primary site of inflammation is the synovial tissue in diverse joints. This chronic autoimmune inflammatory disease causes progressive articular damage, functional loss, and comorbidity, e.g. insulin resistance, dyslipidemia and coronary heart diseases (McInnes 2001).

Multiple sclerosis (MS). MS is an inflammatory demyelinating disease of the central nervous system.
Permanent disability is caused by the loss of axonal function, which correlates with the degree of inflammation (Bruck and Stadelmann 2003).

Inflammatory bowel diseases (IBD). IBD including ulcerative colitis and Crohn's disease describe conditions with chronic or recurring inflammation of the gastrointestinal (GI) tract, especially the large intestine, leading to blood- and mucus-containing diarrhea, severe painful states or GI tissue damage potentially requiring surgical intervention (Kaser et al. 2010).

In addition, persistent chronic inflammation is considered a potential risk factor in the development of other severe diseases, including cancer, atherosclerosis, diabetes or Alzheimer's and Parkinson's disease (Chen et al. 2018).

Cancer. Chronic inflammation is an important factor for cancer development, causing 1 in 4 cancer cases, according to epidemiological data. Inflammation induces DNA damage and chromosomal instability, which enhances tumor cell proliferation and resistance to apoptosis (Hussain and Harris 2007). Tumor metastasis is promoted by angiogenesis, a standard process accompanying inflammation (Mantovani et al. 2008).

\section{Polymer conjugates}

Polymer conjugates (PCs), also known as macromolecular prodrugs, are high molecular weight (HMW) conjugates, typically carrying several molecules of low-molecular-weight drugs or their combination bound to a polymer backbone designed to optimize drug pharmacokinetics (Fig. 1). PCs have a molecular weight $\left(\mathrm{M}_{\mathrm{w}}\right)$ significantly exceeding that of the conjugated drug and their higher hydrodynamic radius decelerates renal excretion of PCs and thus prolongs the circulation of the drug in the blood stream. In addition, PCs generally cannot penetrate healthy endothelium, which minimizes the delivery of conjugated drugs to non-targeted tissues and organs. However, the endothelium of inflamed tissues is more permeable for macromolecules compared to healthy tissues, thus enabling the passive accumulation of PCs. The drug is usually inactive when conjugated to the polymer backbone. The biodegradable spacer between the drug and the polymer chain based on enzymatically or reductively cleavable linkers or hydrolysable bonds enables controlled drug release in the target tissue or cells. Passive accumulation, controlled drug release and the potential introduction of targeting moieties to specific cells or imaging agents make PC with anti-inflammatory 
drugs promising candidates for problematic CID treatment (Natfji et al. 2017).

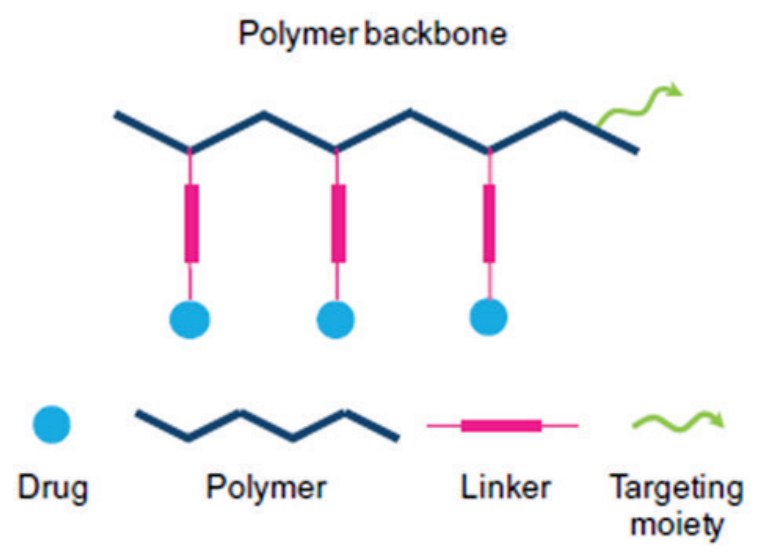

Fig. 1. The scheme of the polymer conjugate with the drug and targeting moiety (modified from (Natfji et al. 2017)).

\section{Polymer backbone type}

The key components of successful PCs are the polymer backbone and the linkage between the drug and the carrier. The polymer backbone of PCs typically serves only as a drug carrier and has no inherent beneficial pharmacological activity. Nevertheless, the "stealth" property of the polymer carrier is its most appreciated feature, improving drug pharmacokinetics and reducing its side effects.

Despite their different origin, i.e. synthetic or natural, and diverse chemical structure, the polymers used in PC design should be water-soluble, biocompatible, non-toxic and non-immunogenic, with functional moieties available for the attachment of drugs, targeting molecules or imaging agents.

The polymer backbone can be biodegradable or non-biodegradable. Water-soluble biodegradable polymers utilized for PCs, which are based on e.g. poly(L-lysine) (Ryser and Shen 1978), poly(L-glutamic acid) (Yang et al. 2011), dextrins (Baldwin and Kiick 2010), chitosan (Onishi et al. 2011) or hyaluronic acid (Shin et al. 2014), are degraded to small fragments, thereby facilitating their excretion from the organism. Frequently, biodegradable natural polymers have to be modified to be able to serve as drug carriers. In spite of their undeniable benefit of biodegradability, some of them become toxic and immunogenic when administered to the body (Markovsky et al. 2012).

Non-biodegradable polymers are not subject to biodegradation and are usually excreted by the kidneys via glomerular filtration up to a certain limit of their $\mathrm{M}_{\mathrm{w}}$, e.g. for the vinylic type of polymers, the limit is approximately $50000 \mathrm{~g} / \mathrm{mol}$. The polymers of higher $\mathrm{M}_{\mathrm{w}}$ are eliminated very slowly via the hepatobiliary route or accumulate in the organism (Markovsky et al. 2012). Despite their size limitation, several benefits of nondegradable polymers frequently used in drug delivery, e.g. non-toxicity, non-immunogenicity, system versatility or potential introduction of various functional groups, outweigh their non-biodegradability. Various water-soluble polymer-drug conjugates are based on numerous non-degradable polymers, e.g. poly(ethylene glycol) (PEG) (Liu et al. 2010), copolymers of $N$-(2-hydroxypropyl)methacrylamide (HPMA) (Liu et al. 2008), poly(vinyl $N$-pyrrolidone) (Timofeevski et al. 1996) or poly(2-oxazoline) (Luxenhofer et al. 2012).

The synthetic polymers are highly attractive in PC design, since they offer countless means for conjugation with biologically active compounds, including reactions in organic solvents or the multivalence of some synthetic polymer precursors. Polymers based on HPMA have been particularly thoroughly investigated in the field of PCs (Kopeček and Kopečková 2010, Kopeček 2013). The high interest in HPMA-based polymers has been aroused by their numerous clear benefits, i.e. biocompatibility and non-immunogenicity, high hydrophicility, which improves the solubility of conjugated drugs, the possibility of introducing numerous different functional groups or the potential co-polymerization of the drugcontaining monomer. In addition, the progress in controlled polymerization techniques, especially controlled radical reversible addition and fragmentation transfer (RAFT) polymerization, has enabled the synthesis of various well-defined HPMA-based polymers with a narrow distribution of molecular weights (Chytil et al. 2018).

In addition to HPMA-based polymers, PEG has largely been used in PCs to prolong blood circulation of low molecular weight (LMW) drugs and proteins. Although several PEGylated therapeutically active proteins have been introduced into clinical practice, no PEG conjugate with LMW drugs has successfully been marketed despite countless publications concerning this topic (Pasut and Veronese 2009). This phenomena can be ascribed to PEG limitations, especially its scarcity of conjugation sites and poor options for copolymerization, allowing only one drug molecule per linear PEG chain (Harris and Chess 2003). In order to overcome this disadvantage, PEG-based dendrimers and block 
copolymers enabling the conjugation of more than one drug per chain have been synthesized (Zacchigna et al. 2011). However, safe excretability should be taken into consideration during the design of the complex PEG-based structures, since the PEG chain is non-biodegradable and its renal threshold is approximately $30 \mathrm{kDa}$ (Baumann et al. 2014). In addition, the widely accepted "golden standard" position of PEG in bioapplication should be carefully reconsidered, since its claimed anti-immunogenicity has lately been disproved (see chapter 4).

The majority of polymer backbones for PCs are charge-neutral, since polycations and polyanions are believed to be notoriously toxic through diverse mechanisms, to accumulate in various organs through nonspecific interactions and to induce significant systemic side effects such as induction of interferon production (Merigan and Regelson 1967, Moreau et al. 2002).

A specific group of polymer precursors for PCs are dendrimers and hyperbranched polymers, which are three-dimensional, highly ordered star-like oligomeric and polymeric macromolecules with numerous functional groups on the surface. The major advantage of using dendrimers for biomedical applications is their monodispersed chemical structure as well as abundance of surface functional groups, which enables a high drug conjugation rate. The physiochemical properties, e.g. solubility, stability, functionality and charge density, are determined by the chemical structure of the monomer unit(s) in the core and surface. The most frequently used dendrimers in drug delivery are polyamidoamine (PAMAM) dendrimers, despite the poor biocompatibility of PAMAM dendrimers with non-modified surface amino groups and their difficult and costly synthesis (Svenson and Tomalia 2005). Hyperbranched polymers and dendrimers based on polyglycerols exhibit good biocompatibility and non-immunogenicity; in addition, their synthesis is relative simple and scalable (Abbina et al. 2017).

A suitable biodegradable linker between the polymer backbone and drug is often a prerequisite for successful treatment. Due to the acidity of the inflammation site, several anti-inflammatory PCs employ a $\mathrm{pH}$-sensitive hydrazone bond. In addition, the presence or higher concentration of specific enzymes in inflamed tissue has led to the design of enzymatically cleavable spacers. PCs intended for CID treatment are described in detail in chapter Polymer conjugates with antiinflammatory activity.
Targeting of polymer conjugates to the inflammation site

The principle of passive targeting of PCs is similar to that of tumor-targeted nanomedicines, known as the enhanced permeability and retention (EPR) effect in solid tumors (Maeda and Matsumura 1989). The endothelium of inflamed tissues, e.g. in arthritic joints or the blood-brain barrier during MS, is more permeable for macromolecules compared to healthy tissues and the rate of accumulation in inflamed tissues is molecular-weight dependent (Kushner and Somerville 1971, Kwon and Prineas 1994, Bennett et al. 2010). In the RA animal model, it was shown that the leaky vasculature of inflamed joints enables permeation by nanomedicines, which are subsequently internalized by activated synoviocytes exhibiting an enhanced endocytic pathway. This phenomenon is referred to as extravasation through leaky vasculature and subsequent inflammatory cell-mediated sequestration (ELVIS). ELVIS may also probably play a role in other CID (Yuan et al. 2012). The shape, size and $\mathrm{M}_{\mathrm{w}}$ of polymer therapeutics are the key factors for their biodistribution and pharmacokinetic profile. With the growing size of polymer carriers, their blood circulation is prolonged and their accumulation in inflamed tissues increases up to a certain limit. Nevertheless, the water-soluble non-biodegradable polymer carriers with a $\mathrm{M}_{\mathrm{w}}$ above $50,000 \mathrm{~g} / \mathrm{mol}$ cannot be excreted by the kidneys and therefore HMW systems should degrade to easily excretable fragments to prevent their persistence in the body (Quan et al. 2010).

The ability of various polymer carriers to accumulate at the inflammation site has been repeatedly shown using diverse imaging techniques. For example, optimal imaging using PEG labeled with a near infrared dye (IRDye $800 \mathrm{CW}$ ) and MRI imaging using an HPMA copolymer labeled with an MRI contrast agent (DOTA $/ \mathrm{Gd}^{3+}$ ) (Wang et al. 2004) demonstrated that both polymer systems accumulated in the joints of arthritic mice.

Due to passive targeting, the application of PCs in drug delivery is expected to increase the drug concentration at the inflammation site while reducing the drug amount in healthy tissues. Thus, molecules with high anti-inflammatory potential but poor biodistribution may become promising drug candidates when conjugated to polymer backbones.

While the drug concentration in inflamed tissues can be increased through passive targeting, directing nanotherapeutics to a specific cell type by the incorporation of targeting ligands into its structure, i.e. 
active targeting, may further improve therapeutic efficiency. Activated macrophages, which play an essential role in CID development and progress, over-express folate receptors and nanomedicines bearing folate have been shown to be actively internalized by these cells (Low and Antony 2004). Angiogenesis and enhanced cell-infiltration at the inflammation site is associated with the over-expression of adhesive molecules, such as integrins, on the surface of macrophages and vascular endothelial cells. The integrintargeted nanomedicines utilizing cyclic forms of RGD oligopeptides exhibited enhanced anti-inflammatory properties in vivo (Koning et al. 2006).

\section{Polymer conjugates with anti-inflammatory activity}

The successful treatment of chronic inflammation poses considerable challenges to modern medicine, including gradual and controlled cellular death of specific immune cells without interfering with healthy tissues. The concept of drug conjugation can be widely applied within the context of inflammation, enabling drug accumulation at inflammation sites and controlled release in target tissue or cells. Therefore, several polymer conjugates with diverse anti-inflammatory drugs have been designed and their biological activity has been evaluated.

Some of the most frequently used and most potent anti-inflammatory drugs are glucocorticoids (GC), e.g. dexamethasone (Dex). However, the long-term application of free GC induces severe side effects. Therefore, a HPMA copolymer conjugate with Dex bound via a $\mathrm{pH}$-sensitive bond was synthesized. The pH-sensitive hydrazone bond between the polymer backbone and Dex prevented drug release at $\mathrm{pH} 7.4$ (corresponding to the blood $\mathrm{pH}$ ) and enabled sustained Dex release in the acidic environment ( $\mathrm{pH}$ 4.4-6) which is present at the site of RA; $14 \%$ of the drug was released within 14 days at $\mathrm{pH} 5$. Compared to free Dex, the Dex-polymer conjugate exhibited longer lasting and enhanced joint protection and anti-inflammatory effect in an in vivo rat model with arthritis, resulting in complete restoration of ankle size within 3 days (Liu et al. 2008).

The PEG backbone also served as polymer carrier for Dex bound via a $\mathrm{pH}$-sensitive hydrazone bond. To overcome the scarcity of PEG conjugation sites, a linear multifunctional PEG-Dex conjugate was synthesized by the reaction of the functionalized short PEG chain with Dex-bearing monomers using coppercatalyzed click chemistry. Despite the same chemical structure of the biodegradable linker, the Dex release was much slower for PEG conjugates than for HPMA copolymer conjugates (the release rate from PEG-Dex conjugates was $0.5 \%$ per day, while for HPMA copolymer-Dex conjugates it reached $1 \%$ released Dex per day), probably due to the different chemical vicinity of the hydrazone bond. Therefore, the anti-inflammatory activity of the PEG-Dex conjugate was milder than in the case of HPMA copolymer-Dex conjugate, leading to only partial amelioration of joint inflammation in a rat model of arthritis (Liu et al. 2010).

Apart from acidic cleavable GC polymer conjugates, enzymatically cleavable linkers were utilized to conjugate diverse GCs to polymer backbones. Dex conjugate with poly(1-vinyl-2-pyrrolidone) with an esterase-sensitive spacer was synthesized by copolymerization of the Dex-bearing monomer and 1-vinyl-2-pyrrolidone (Timofeevski et al. 1996). Dex and other GCs were conjugated via ester linkers to diverse hydrophilic polymers, e.g. dextran (Penugonda et al. 2008), chitosan (Onishi et al. 2011), poly((dimethylamino)ethyl methacrylate) (Keely et al. 2009) or dendrimers (Inapagolla et al. 2010). However, their application in vivo and controlled release at the inflammation site is rather questionable given the abundance of esterase in the plasma.

NSAID, e.g. indomethacin, ibuprofen, naproxen, are widely used to reduce inflammation and pain in CID. However, their long-term systemic application may cause severe gastrointestinal difficulties. To enhance antiinflammatory activity and reduce side effects, naproxen was conjugated to a PEG-based carrier via oxidativesensitive spacer, a phenylboronic ester, cleavable after exposure to ROS, which are over-produced in inflamed tissue; up to $92 \%$ of the drug was released in the presence of $\mathrm{H}_{2} \mathrm{O}_{2}$, while almost no drug release was observed in the absence of ROS (Qiu et al. 2015). A macromolecular prodrug of naproxen based on PAMAM dendrimers was designed to improve oral bioavailability. Naproxen-dendrimer conjugates with a lactate ester linker exhibited enhanced transepithelial transport, stability in human plasma and controlled release in liver cells (Najlah et al. 2007). Naproxen or other NSAIDs, e.g. indomethacin, have been conjugated to natural biodegradable polymer carriers, i.e. dextran (Mária et al. 1986) or chitosan (Isabella et al. 1996), via an ester linker cleavable by esterase-catalyzed hydrolysis. However, their wide application in inflammation treatment has not been realized. 
Polymer conjugates with NSAIDs have gained interest in colon-specific drug delivery intended for IBD. To obtain a colon-specific delivery, azoreductase enzymes, selectively present in the colon, were exploited by introducing an azo linker between the polymer carrier and the drug molecule. An anti-inflammatory drug widely used in IBD treatment, 5-aminosalicylic acid (5-ASA), was conjugated to various water-soluble polymer carriers via an azo linker cleavable by colonic microflora (Philip and Philip 2010). The bioadhesive HPMA copolymer-5ASA conjugate was prepared by copolymerization of an azo-linked 5-ASA-containing monomer with HPMA and the fucosylamine-containing comonomer (the bioadhesive component). The introduction of the fucosylamine moiety enabled enhanced adherence to guinea pig colon due to the site-specific binding of carbohydrate moieties complementary to colonic mucosal lectins. The incorporation of 5-ASA-bearing aromatic side-chains into HPMA copolymers enabling colonspecific drug release further increased their adherence probably through the combination of non-specific hydrophobic binding and specific recognition (Kopečková et al. 1994).

Analogously, 5-ASA conjugated via an azo linker to short PEG chains of $M_{w}$ of $4,000 \mathrm{~g} / \mathrm{mol}$ exhibited satisfactory drug release in the colon with minimized drug release and absorption in the upper intestine. The application of the PEG-based 5-ASA conjugate led to an enhanced anti-inflammatory effect, including bodyweight gain, improved tissue histology and proinflammatory cytokine decrease, in vivo using mice with induced colitis (Canevari et al. 2009). In addition, colon-targeted conjugates with 5-ASA or other NSAIDs based on PAMAM dendrimers (Wiwattanapatapee et al. 2003) or polysaccharides, including hydroxypropyl cellulose, dextran or chitosan, have been designed and synthesized (Larsen et al. 1989, Zou et al. 2005).

CID treatment often requires the application of immunomodulating agents, especially methotrexate (MTX), since the disease is often associated with autoimmunity. Most PCs with MTX were initially developed for cancer therapy. However, their application in anti-inflammatory CID treatment is very promising. Due to the accumulation of macromolecules in inflamed tissues, the long circulation time of albumin (19 days) and controlled MTX release by enzymes overexpressed in inflamed synovium (i.e. cathepsin B and plasmin), an MTX conjugate of human serum albumin
$\left(\mathrm{M}_{\mathrm{w}} \approx 67,000 \mathrm{~g} / \mathrm{mol}\right)$ exhibited enhanced in vivo activity in murine collagen-induced arthritis (Fiehn et al. 2008).

Protease-cleavable oligopeptide linkers have been also utilized in the design of MTX conjugates of HPMA copolymers or hyaluronic acid. To enhance its anti-inflammatory potential, an HPMA copolymer-based MTX conjugate was decorated with biotin molecules for active targeting to macrophages. The oligopeptide spacer (GFLG) of the HPMA-copolymer conjugate enabled MTX release in lysosomes after the cellular uptake of the PC. However, its in vivo activity has not been demonstrated yet (Russell-Jones and Mcewan 2004). The hyaluronic acid conjugate of MTX utilized two lysosomal enzyme-cleavable linkers, i.e. GFLG and NFF. Despite MTX release from both conjugates by lysosomal enzymes in vitro, significant reduction in knee swelling of rats with arthritis was observed only after intraarticular injection of the conjugate with an NFF spacer (Shin et al. 2014).

Active targeting to folate receptors in macrophages was employed for drug delivery to the inflammation site using MTX conjugates of PAMAM dendrimers or biodegradable dextrans (Qi et al. 2015, Yang et al. 2016). The introduction of folic acid (FA) as a targeting moiety enhanced the cellular uptake of both conjugates into macrophages in vitro. The PAMAM conjugate of MTX showed a similar preventive effect on the development of arthritis in rats to free MTX; however, no spleen toxicity was observed for the MTX conjugate in comparison to the free drug. A biodegradable dextran-MTX conjugate with FA possessed improved biodistribution at the inflammation site and stronger remission of arthritis in mice through the inhibition of proinflammatory cytokines in comparison to both free MTX and the non-targeted corresponding MTX conjugate.

\section{Polymer-promoted inflammation and immunogenicity}

Immunogenicity is defined as the ability of a substance to provoke an immune response. An immune response could be desirable, in the case of vaccines, or could be an unwanted side effect of the material. When polymers are used as anti-inflammatory drug carriers, the activation of the immune system should be as low as possible (Farrera and Fadeel 2015).

Polymer physicochemical properties determine their interaction with the immune system. The majority of 
nanosized drug delivery systems are based on non-water soluble materials, e.g. polyester or metal nanoparticles, carbon nanotubes, which are generally coated with hydrophilic polymers, i.e. PEG, HPMA copolymers, in order to improve the system biocompatibility, nontoxicity and non-immunogenicity (Dobrovolskaia and McNeil 2007). If they are not protected by coating, e.g. with PEG, they interact with plasma proteins, which makes them easily recognizable for immune cells, especially macrophages (Owens and Peppas 2006). Nevertheless, the majority of polymer-drug conjugates are based on hydrophilic polymers and therefore they are supposed not to induce undesired immune reactions in vivo. One of the most frequently used polymers in PCs has been developed as a safe plasma expander and in addition the biocompatibility and non-immunogenicity of HPMA copolymer-based carriers have been repeatedly shown in vivo and clinical trials (Gaspar and Duncan 2009, Říhová and Kováŕ 2010).

PEG-based therapeutics has received a great deal of interest in the delivery of therapeutic proteins in clinical practice (Jevsevar et al. 2010). PEGylation of these proteins considerably prolongs their blood circulation, thereby maintaining their biological activity. Despite its high popularity in nanotherapeutics design, several studies have shown that the repeated application of PEG may lead to immune response and formation of anti-PEG antibodies (Zhang et al. 2016).

The surface charge of PCs is one of the key factors influencing the immune response of the organism to PC application. Positively or negatively charged polymers are usually quickly entrapped by RES and eliminated by the liver (He et al. 2010).

The influence of the polymer carrier on the immune system is crucial in the design of antiinflammatory drug-polymer conjugates, since unbalanced chronic inflammation is very sensitive to any external or internal proinflammatory stimuli. Therefore, we believe that PCs based on biocompatible non-immunogenic synthetic polymers, e.g. HPMA copolymers, would be very promising in the treatment of various CIDs.

\section{Conclusions}

Chronic inflammation is believed to cause numerous severe diseases, including RA, MS or some cancers, and its successful resolution often remains problematic. Polymer-drug conjugates based on hydrophilic and biocompatible materials have attracted attention in the modern treatment of inflammation or cancer due to targeted drug delivery and controlled drug release. We have reviewed the relationship between inflammation and inflammatory-related diseases with polymer conjugates, emphasizing the anti-inflammatory activity of polymer-drug conjugates and potential polymer-promoted inflammation and immunogenicity.

\section{Conflict of Interest}

There is no conflict of interest.

\section{Acknowledgements}

The work was supported by the Ministry of Education, Youth and Sports of $\mathrm{CR}$ within the National Sustainability Program I, Project LO1507 POLYMAT.

\section{References}

ABBINA S, VAPPALA S, KUMAR P, SIREN EMJ, LA CC, ABBASI U, BROOKS DE, KIZHAKKEDATHU JN: Hyperbranched polyglycerols: recent advances in synthesis, biocompatibility and biomedical applications. J Mater Chem B 5: 9249-9277, 2017.

ANDERSON JM, RODRIGUEZ A, CHANG DT: Foreign body reaction to biomaterials. Semin Immunol 20: 86-100, 2008.

ASHLEY NT, WEIL ZM, NELSON RJ: Inflammation: Mechanisms, costs, and natural variation. Annu Rev Ecol Evol Syst 43: 385-406, 2012.

BALDWIN AD, KIICK KL: Polysaccharide-modified synthetic polymeric biomaterials. Biopolymers 94: 128-140, 2010.

BAUMANN A, TUERCK D, PRABHU S, DICKMANN L, SIMS J: Pharmacokinetics, metabolism and distribution of PEGs and PEGylated proteins: quo vadis? Drug Discov Today 19: 1623-1631, 2014.

BENNETT J, BASIVIREDDY J, KOLLAR A, BIRON KE, REICKMANN P, JEFFERIES WA, MCQUAID S: Bloodbrain barrier disruption and enhanced vascular permeability in the multiple sclerosis model EAE. J Neuroimmunol 229: 180-191, 2010. 
BIANCHI ME: DAMPs, PAMPs and alarmins: all we need to know about danger. J Leukoc Biol 81: 1-5, 2007.

BODOLAY E, KOCH AE, KIM J, SZEGEDI G, SZEKANECZ Z: Angiogenesis and chemokines in rheumatoid arthritis and other systemic inflammatory rheumatic diseases. J Cell Mol Med 6: 357-376, 2002.

BRUCK W, STADELMANN C: Inflammation and degeneration in multiple sclerosis. Neurol Sci 24 (Suppl 5): S265-S267, 2003.

CANEVARI M, CASTAGLIUOLO I, BRUN P, CARDIN M, SCHIAVON M, PASUT G, VERONESE FM: Poly(ethylene glycol)-mesalazine conjugate for colon specific delivery. Int J Pharm 368: 171-177, 2009.

CHEN L, DENG H, CUI H, FANG J, ZUO Z, DENG J, LI Y, WANG X, ZHAO L: Inflammatory responses and inflammation-associated diseases in organs. Oncotarget 9: 7204-7218, 2018.

CHYTIL P, KOZIOLOVA E, ETRYCH T, ULBRICH K: HPMA Copolymer-drug conjugates with controlled tumorspecific drug release. Macromol Biosci 18: 1700209, 2018.

COUSSENS LM, WERB Z: Inflammation and cancer. Nature 420: 860-867, 2002.

DINARELLO CA: Anti-inflammatory agents: Present and future. Cell 140: 935-950, 2010.

DOBROVOLSKAIA MA, MCNEIL SE: Immunological properties of engineered nanomaterials. Nat Nanotechnol 2: 469-478, 2007.

EL-GABALAWY H, GUENTHER LC, BERNSTEIN CN: Epidemiology of immune-mediated inflammatory diseases: incidence, prevalence, natural history, and comorbidities. J Rheumatol Suppl 85: 2-10, 2010.

ELLIOTT MR, CHEKENI FB, TRAMPONT PC, LAZAROWSKI ER, KADL A, WALK SF, PARK D, WOODSON RI, OSTANKOVICH M, SHARMA P, LYSIAK JJ, HARDEN TK, LEITINGER N, RAVICHANDRAN KS: Nucleotides released by apoptotic cells act as a find-me signal to promote phagocytic clearance. Nature $\mathbf{4 6 1}$ : 282-286, 2009.

FADOK VA, BRATTON DL, KONOWAL A, FREED PW, WESTCOTT JY, HENSON PM: Macrophages that have ingested apoptotic cells in vitro inhibit proinflammatory cytokine production through autocrine/paracrine mechanisms involving TGF-beta, PGE2, and PAF. J Clin Invest 101: 890-898, 1998.

FARRERA C, FADEEL B: It takes two to tango: Understanding the interactions between engineered nanomaterials and the immune system. Eur J Pharm Biopharm 95: 3-12, 2015.

FIEHN C, KRATZ F, SASS G, MULLER-LADNER U, NEUMANN E: Targeted drug delivery by in vivo coupling to endogenous albumin: an albumin-binding prodrug of methotrexate (MTX) is better than MTX in the treatment of murine collagen-induced arthritis. Ann Rheum Dis 67: 1188-1191, 2008.

FOX S, LEITCH AE, DUFFIN R, HASLETT C, ROSSI AG: Neutrophil apoptosis: relevance to the innate immune response and inflammatory disease. J Innate Immun 2: 216-227, 2010.

FRANCESCHI C, CAMPISI J: Chronic inflammation (inflammaging) and its potential contribution to age-associated diseases. J Gerontol A Biol Sci Med Sci 69 (Suppl 1): S4-S9, 2014.

GASPAR R, DUNCAN R: Polymeric carriers: preclinical safety and the regulatory implications for design and development of polymer therapeutics. Adv Drug Deliv Rev 61: 1220-1231, 2009.

HARRIS JM, CHESS RB: Effect of pegylation on pharmaceuticals. Nat Rev Drug Discov 2: 214-221, 2003.

HE C, HU Y, YIN L, TANG C, YIN C: Effects of particle size and surface charge on cellular uptake and biodistribution of polymeric nanoparticles. Biomaterials 31: 3657-3666, 2010.

HEADLAND SE, NORLING LV: The resolution of inflammation: Principles and challenges. Semin Immunol 27: 149-160, 2015.

HUSSAIN SP, HARRIS CC: Inflammation and cancer: an ancient link with novel potentials. Int $J$ Cancer 121: 2373-2380, 2007.

IKOBA U, PENG H, LI H, MILLER C, YU C, WANG Q: Nanocarriers in therapy of infectious and inflammatory diseases. Nanoscale 7: 4291-4305, 2015.

INAPAGOLLA R, GURU BR, KURTOGLU YE, GAO X, LIEH-LAI M, BASSETT DJ, KANNAN RM: In vivo efficacy of dendrimer-methylprednisolone conjugate formulation for the treatment of lung inflammation. Int J Pharm 399: 140-147, 2010.

ISABELLA O, KHALED A, ELISABETTA G, CRISTINA P, VITTORIO Z: Chitosan-indomethacin conjugates. Effect of different substituents on the polysaccharide molecule on drug release. Arch Pharm 329: 245-250, 1996. 
JANSSENS S, BEYAERT R: Role of Toll-like receptors in pathogen recognition. Clin Microbiol Rev 16: 637-646, 2003.

JEVSEVAR S, KUNSTELJ M, POREKAR VG: PEGylation of therapeutic proteins. Biotechnol J 5: 113-128, 2010.

KASER A, ZEISSIG S, BLUMBERG RS: Inflammatory bowel disease. Annu Rev Immunol 28: 573-621, 2010.

KEELY S, RYAN SM, HADDLETON DM, LIMER A, MANTOVANI G, MURPHY EP, COLGAN SP and BRAYDEN DJ: Dexamethasone-pDMAEMA polymeric conjugates reduce inflammatory biomarkers in human intestinal epithelial monolayers. $J$ Control Release 135: 35-43, 2009.

KONING GA, SCHIFFELERS RM, WAUBEN MH, KOK RJ, MASTROBATTISTA E, MOLEMA G, TEN HAGEN TL, STORM G: Targeting of angiogenic endothelial cells at sites of inflammation by dexamethasone phosphate-containing RGD peptide liposomes inhibits experimental arthritis. Arthritis Rheum 54: 1198-1208, 2006.

KOPEČEK J: Polymer-drug conjugates: Origins, progress to date and future directions. Adv Drug Deliv Rev 65: 49-59, 2013.

KOPEČEK J, KOPEČKOVÁ P: HPMA copolymers: origins, early developments, present, and future. Adv Drug Deliv Rev 62: 122-149, 2010.

KOPEČKOVÁ P, RATHI R, TAKADA S, ŘÍHOVÁ B, BERENSON MM, KOPEČEK J: Bioadhesive N-(2hydroxypropyl) methacrylamide copolymers for colon-specific drug delivery. J Control Release 28: 211-222, 1994.

KOSTKA L, ETRYCH T: High-molecular-weight HPMA-based polymer drug carriers for delivery to tumor. Physiol Res 65 (Suppl 2): S179-S190, 2016.

KUSHNER I, SOMERVILLE JA: Permeability of human synovial membrane to plasma proteins. Relationship to molecular size and inflammation. Arthritis Rheum 14: 560-570, 1971.

KWON EE, PRINEAS JW: Blood-brain barrier abnormalities in longstanding multiple sclerosis lesions. An immunohistochemical study. J Neuropathol Exp Neurol 53: 625-636, 1994.

LARSEN C, HARBOE E, JOHANSEN M, OLESEN HP: Macromolecular prodrugs. XVI. Colon-targeted delivery-comparison of the rate of release of naproxen from dextran ester prodrugs in homogenates of various segments of the pig gastrointestinal (GI) tract. Pharm Res 6: 995-999, 1989.

LIDICKY O, SIROVA M, ETRYCH T: HPMA copolymer-based polymer conjugates for the delivery and controlled release of retinoids. Physiol Res $\mathbf{6 5}$ (Suppl 2): S233-S241, 2016.

LIU XM, QUAN LD, TIAN J, LAQUER FC, CIBOROWSKI P, WANG D: The syntheses of click PEG-dexamethasone conjugates for the treatment of rheumatoid arthritis. Biomacromolecules 11: 2621-2628, 2010.

LIU XM, QUAN LD, TIAN J, ALNOUTI Y, FU K, THIELE GM, WANG D: Synthesis and evaluation of a well-defined HPMA copolymer-dexamethasone conjugate for effective treatment of rheumatoid arthritis. Pharm Res 25: 2910-2919, 2008.

LOW PS, ANTONY AC: Folate receptor-targeted drugs for cancer and inflammatory diseases. Adv Drug Deliv Rev 56: 1055-1058, 2004.

LUXENHOFER R, HAN Y, SCHULZ A, TONG J, HE Z, KABANOV AV, JORDAN R: Poly(2-oxazoline)s as polymer therapeutics. Macromol Rapid Commun 33: 1613-1631, 2012.

MAEDA H, MATSUMURA Y: Tumoritropic and lymphotropic principles of macromolecular drugs. Crit Rev Ther Drug Carrier Syst 6: 193-210, 1989.

MANTOVANI A, ALLAVENA P, SICA A, BALKWILL F: Cancer-related inflammation. Nature 454: 436-444, 2008.

MÁRIA A, JÁNOS P, ÉVA C, FERENC T: Polymeric prodrugs, 5. Dextran-bound antirheumatic agent naproxen. Makromol Chem 187: 2073-2080, 1986.

MARKOVSKY E, BAABUR-COHEN H, ELDAR-BOOCK A, OMER L, TIRAM G, FERBER S, OFEK P, POLYAK D, SCOMPARIN A, SATCHI-FAINARO R: Administration, distribution, metabolism and elimination of polymer therapeutics. J Control Release 161: 446-460, 2012.

MCINNES IB: Rheumatoid arthritis. From bench to bedside. Rheum Dis Clin North Am 27: 373-387, 2001.

MELNICOFF MJ, HORAN PK, MORAHAN PS: Kinetics of changes in peritoneal cell populations following acute inflammation. Cell Immunol 118: 178-191, 1989. 
MERIGAN TC, REGELSON W: Interferon induction in man by a synthetic polyanion of defined composition. $N$ Engl J Med 277: 1283-1287, 1967.

MOREAU E, DOMURADO M, CHAPON P, VERT M, DOMURAD D: Biocompatibility of polycations: in vitro agglutination and lysis of red blood cells and in vivo toxicity. J Drug Target 10: 161-173, 2002.

NAJLAH M, FREEMAN S, ATTWOOD D, D'EMANUELE A: In vitro evaluation of dendrimer prodrugs for oral drug delivery. Int J Pharm 336: 183-190, 2007.

NATFJI AA, OSBORN HMI, GRECO F: Feasibility of polymer-drug conjugates for non-cancer applications. Curr Opin Colloid Interface Sci 31: 51-66, 2017.

ONISHI H, SAITO Y, SASATSU M, MACHIDA Y: Kinetic analysis of in vitro and in vivo release of prednisolone from the conjugate of glycol-chitosan and succinyl-prednisolone. Int J Pharm 410: 17-22, 2011.

OWENS DE 3RD, PEPPAS NA: Opsonization, biodistribution, and pharmacokinetics of polymeric nanoparticles. Int J Pharm 307: 93-102, 2006.

PASUT G, VERONESE FM: PEG conjugates in clinical development or use as anticancer agents: An overview. Adv Drug Deliv Rev 61: 1177-1188, 2009.

PENUGONDA S, KUMAR A, AGARWAL HK, PARANG K, MEHVAR R: Synthesis and in vitro characterization of novel dextran-methylprednisolone conjugates with peptide linkers: effects of linker length on hydrolytic and enzymatic release of methylprednisolone and its peptidyl intermediates. J Pharm Sci 97: 2649-2664, 2008.

PHILIP AK, PHILIP B: Colon targeted drug delivery systems: a review on primary and novel approaches. Oman Med $J$ 25: 79-87, 2010.

POLA R, JANOUSKOVA O, ETRYCH T: The pH-dependent and enzymatic release of cytarabine from hydrophilic polymer conjugates. Physiol Res 65 (Suppl 2): S225-S232, 2016.

QI R, MAJOROS I, MISRA AC, KOCH AE, CAMPBELL P, MAROTTE H, BERGIN IL, CAO Z, GOONEWARDENA S, MORRY J, ZHANG S, BEER M, MAKIDON P, KOTLYAR A, THOMAS TP, BAKER JR JR: Folate receptor-targeted dendrimer-methotrexate conjugate for inflammatory arthritis. J Biomed Nanotechnol 11: 1431-1441, 2015.

QIU FY, ZHANG M, JI R, DU FS, LI ZC: Oxidation-responsive polymer-drug conjugates with a phenylboronic ester linker. Macromol Rapid Commun 36: 2012-2018, 2015.

QUAN L-D, YUAN F, LIU X-M, HUANG J-G, ALNOUTI Y, WANG D: Pharmacokinetic and biodistribution studies of N-(2-hydroxypropyl)methacrylamide (HPMA) copolymer-dexamethasone conjugates in adjuvant-induced arthritis (AA) rat model. Mol Pharm 7: 1041-1049, 2010.

RAJAKARIAR R, LAWRENCE T, BYSTROM J, HILLIARD M, COLVILLE-NASH P, BELLINGAN G, FITZGERALD D, YAQOOB MM, GILROY DW: Novel biphasic role for lymphocytes revealed during resolving inflammation. Blood 111: 4184-4192, 2008.

RUSSELL-JONES G, MCEWAN J: Amplification of biotin-mediated targeting. Assignee: Access Pharmaceuticals Australia Pty Ltd. Patent No. WO2004045647A1, 2004.

RYSER HJP, SHEN WC: Conjugation of methotrexate to poly(L-lysine) increases drug transport and overcomes drug resistance in cultured cells. Proc Natl Acad Sci U S A 75: 3867-3870, 1978.

ŘÍHOVÁ B, KOVÁŘ M: Immunogenicity and immunomodulatory properties of HPMA-based polymers. Adv Drug Deliv Rev 62: 184-191, 2010.

SHIN JM, KIM SH, THAMBI T, YOU DG, JEON J, LEE JO, CHUNG BY, JO DG, PARK JH: A hyaluronic acidmethotrexate conjugate for targeted therapy of rheumatoid arthritis. Chem Commun (Camb) 50: 7632-7635, 2014.

SUGIMOTO MA, SOUSA LP, PINHO V, PERRETTI M, TEIXEIRA MM: Resolution of inflammation: what controls its onset? Front Immunol 7: 160, 2016.

SVENSON S, TOMALIA DA: Dendrimers in biomedical applications--reflections on the field. Adv Drug Deliv Rev 57: 2106-2129, 2005.

TIMOFEEVSKI SL, PANARIN EF, VINOGRADOV OL, NEZHENTSEV MV: Anti-inflammatory and antishock water-soluble polyesters of glucocorticoids with low level systemic toxicity. Pharm Res 13: 476-480, 1996.

VAN DEN BERG JM, WEYER S, WEENING JJ, ROOS D, KUIJPERS TW: Divergent effects of tumor necrosis factor alpha on apoptosis of human neutrophils. J Leukoc Biol 69: 467-473, 2001. 
WANG D, MILLER SC, SIMA M, PARKER D, BUSWELL H, GOODRICH KC, KOPECKOVA P, KOPECEK J: The arthrotropism of macromolecules in adjuvant-induced arthritis rat model: a preliminary study. Pharm Res 21: 1741-1749, 2004.

WIWATTANAPATAPEE R, LOMLIM L, SARAMUNEE K: Dendrimers conjugates for colonic delivery of 5-aminosalicylic acid. $J$ Control Release 88: 1-9, 2003.

WRIGHT HL, MOOTS RJ, BUCKNALL RC, EDWARDS SW: Neutrophil function in inflammation and inflammatory diseases. Rheumatology (Oxford) 49: 1618-1631, 2010.

YANG D, VAN S, LIU J, WANG J, JIANG X, WANG Y, YU L: Physicochemical properties and biocompatibility of a polymer-paclitaxel conjugate for cancer treatment. Int J Nanomedicine 6: 2557-2566, 2011.

YANG M, DING J, ZHANG Y, CHANG F, WANG J, GAO Z, ZHUANG X, CHEN X: Activated macrophagetargeted dextran-methotrexate/folate conjugate prevents deterioration of collagen-induced arthritis in mice. J Mater Chem B 4: 2102-2113, 2016.

YUAN F, QUAN LD, CUI L, GOLDRING SR, WANG D: Development of macromolecular prodrug for rheumatoid arthritis. Adv Drug Deliv Rev 64: 1205-1219, 2012.

ZACCHIGNA M, CATENI F, DRIOLI S, BONORA GM: Multimeric, multifunctional derivatives of poly(ethylene glycol). Polymers 3: 1076, 2011

ZHANG P, SUN F, LIU S, JIANG S: Anti-PEG antibodies in the clinic: Current issues and beyond PEGylation. J Control Release 244: 184-193, 2016.

ZOU M, OKAMOTO H, CHENG G, HAO X, SUN J, CUI F, DANJO K: Synthesis and properties of polysaccharide prodrugs of 5-aminosalicylic acid as potential colon-specific delivery systems. Eur J Pharm Biopharm 59: $155-160,2005$. 